\title{
Self-assessment in performance
}

\section{Ryan Daniel}

ryan.daniel@jcu.edu.au

This article examines the issue of self-assessment of musical performance and the role of the learner in this process, with particular reference to the Australian context. Initially, traditional methods of assessment are discussed and references made to alternative methodologies in action. Following this, the rationale for and structure of a new method of self-critical assessment is outlined. The initial trial is discussed along with the evaluative questionnaire. The resultant data are then analysed and discussed, as are the implications for adopting and for developing this method.

Tertiary institutions in Australia are being forced to re-evaluate their programmes and to undergo rapid change. The current economic climate and the pressure of decreased funding for the tertiary-sector have engendered a radical restructuring of and refocus for many institutions. This is particularly the case in the arts: the ever-increasing need to justify the worth of this area in the university sector has never been so critical. Music is an area of particular concern. Horn (1996: 537) suggests 'musicians in education are in a continual battle to maintain the integrity of the subject'. Whilst it can be argued that music institutions have often struggled to survive financially, Wills (2000: 16) suggests that 'with all the cutbacks and the difficulties that universities are having in general, music [today] is faring even worse'. Wills' concern is real: whereas an engineering graduate, for example, will contribute to the building of a bridge, and a medical student will treat a patient, with music the results are not as self-evidently practical. Many cannot see the immediate personal or societal advantage of a music degree. Part of the urgent need in music education, particularly at the tertiary level, is a refocus of the pedagogical ethos of courses to target the production of graduates whose skills will be directly marketable to the community. While many music institutions in Australia still have a predominantly 'classical' focus, many have changed their emphasis to focus on other styles or to become more community minded and interactive.

In line with the need to change the focus of their degrees, many Australian institutions have been challenged to make radical and timely changes in other areas, including procedures for assessment. Musical performance, in particular, poses many problems in terms of assessment. How does one objectively assess an art that is inherently personal and individual, and exists through, rather than in, time? In a maths exam there is typically but one answer to a problem, but there are many ways of performing a Mozart sonata, a Schubert Lied, or a jazz standard by Duke Ellington. Obviously, basic stylistic tenets for the performance of a musical work must be observed, but each individual's interpretation is likely to be different. In addition, one person's assessment of a performance may differ 
greatly from another's, given the various factors that influence individual perceptions. While general observations may be similar, evaluations of many performances often differ widely, particularly of those at a high level, where the interpretative aspects become more critical to the overall presentation. Most university music academics have participated as examiners in performance assessment panels and thus recognize that rarely does the final result come easily or unanimously. Performance assessment situations are also often problematic for students. Usually, unless some form of recording is made, there is no lasting record of the event. As a result, many students have nothing to refer back to, other than memories of the event, which are often dominated by anxiety, nerves and tension. Potentially, this causes a problem in terms of the opportunity for students to reflect on their performances. As a result, they often rely on the opinions of external assessors, be they members of a panel, their teachers, their peers or an audience.

Several authors discuss the challenges associated with assessment and the arts. Ross, Radnor, Mitchell \& Bierton (1993: xi) argued that 'absent from current assessment practice in the arts is any serious encouragement of the pupil's own act of self-appraisal'. They then describe the introduction of the National Oracy Project, which directly involved students in self-appraisal of their work, via discussion with their pedagogues. Some tertiary institutions have also taken the lead in promoting self-assessment. The Performance and Communication Skills department at the Guildhall School of Music and Drama in London currently promotes critical reflection and self-assessment. As part of course requirements, self-assessment becomes an 'increasingly important element in each student's learning profile' (Guildhall School of Music \& Drama, n.d.: 32). This involves the maintenance of a self-reflective diary on aspects of teaching and learning and the option of presenting a selfassessment folio.

Several authors refer to assessment and its complexities within the musical environment. Stowasser (1996: 551) describes the process of awarding marks for music performance as 'hazardous'. She proposes an alternative to the traditional externally based method of assessing performance in terms of establishing 'portfolio assessment in which assignments are collected complete with reflective comments, both from the teacher and from the student'. With regard to music specifically, she suggests that students present performances via 'recordings on cassette and video' and that these constitute a portfolio. She also discusses the benefits of having a portfolio of such works for future employment purposes. Smythe (2000: 17) also argues that 'the tape recorder has enormous value as a teaching aid' and incorporates this in his teaching.

Baker-Jordan (1999: 22) considers that without the addition of audio or video technology within the learning environment, the feedback which students obtain from their teachers, coaches, or audiences can not only be biased, but also has an effectiveness which is based on the success of the 'interpersonal communication process'. She describes the factors that affect this process as:

- the external assessor's ability to communicate a critique or evaluation of the student's performance level and progress;

- $\quad$ the medium by which this is achieved; and

- how the relationship between the teacher and student affects the student's assimilation of the critical assessment process. (Baker-Jordan 1999). 
This suggests that the quality of the relationship between teacher and student has a distinct effect on the success or otherwise of each student's absorption of the comments made by the teacher or mentor. Those students who fear their teachers or are unable to discern the most relevant material may have distinct trouble when interpreting the assessor's comments. In terms of an alternative means of assessment, Baker-Jordan (1999: 22-3) states that the advantage with videotaping is that students receive feedback, which is 'accurate and valid because it is direct and bypasses the interpersonal communication process'. She also feels that videotaping is superior to audio recording as it 'involves both the visual and auditory senses, which increases the effectiveness of the learning'. This would also imply, however, that students are capable of critically analysing the various technical, musical, stylistic and presentational aspects of their performances.

Videotaping appears to offer considerable advantages in a variety of music education situations and is used by a number of pedagogues. Lynch (1998: 40) began by using audio taping in his instrumental school teaching, but soon moved on to video recording when he realized 'how much easier it was to assess individuals when you can see them as well as hear the music they played'. At the beginning of lessons, Lynch shows students a video recording of the previous lesson's final performance, following which he asks them to take notes and discuss what is good and what could be improved. In this way, he involves them in the process of assessment and the students have both an aural and visual record of their progress. Carty (2000: n.p.) also discusses the benefits of incorporating a video portfolio, enabling students to maintain a 'record of their progress' over time and to reflect critically on their playing at various points. Jay (2000: n.p.) describes the benefits of video recording and considers that 'children hear themselves in a totally different way when they are not playing'. This observation comes from her experience of incorporating video footage during lessons. Others, including Benson (2000), incorporate videotaping within their teaching, for the purpose of engaging students in reflection and self-assessment.

It is commonplace within music education that external assessment plays a significant part in the development of a student's performance skills, be this in the form of teacher, examiner, the critical response from an audience or, ultimately, from the professional critic. The issue as to when self-assessment skills become critical is worth considering and raises a number of concomitant questions. Should this reflective skill be promoted at an early age? Should it be nurtured progressively and in greater depth as students mature? Is it a skill that can be taught, or is it intrinsic only to the make-up of more talented students? Does reflective evaluation promote the most effective means of developing independent learners?

It would seem that skills in self-assessment are particularly important in tertiary study when students are in an environment where they are encouraged, and able, to develop skills in thinking independently and reflecting dispassionately on their practice and performance. Renshaw (2000: n.p.) discusses the issue of making students more responsible for their assessment and refers to a 'growing emphasis on self-directed learning and reflective practice in both individual tuition and collaborative work'. Murray-Harvey argues that self-assessment or self-evaluation at the tertiary level is,

an important attribute to be developed in a learner ... [and] is a natural extension of more general efforts to encourage students' greater awareness of and control over the learning process. (Murray-Harvey, 1997: 178-9). 
Why is it often a problem in tertiary music institutions that students are unable to comment critically in any depth on their performances in a lesson, master class or public performance? Is this the fault of the student, the student's past or current teacher(s) or the institutional setting? Another considerable problem in tertiary music education is the reliance of the student on the teacher, as musical guru or 'as the gatekeeper of knowledge of the fount of wisdom' (Francis, 1997: 137). Coupled with this is the frequency with which students often rely on recordings by others as the means by which to shape and develop their own performance skills, rather than take responsibility for investigating, formulating and reflecting on their own interpretations.

In the tertiary sector, the traditional emphasis is often on external assessment of performance. On many occasions, there is very little overt self-reflection or analysis done by the student in regard to playing, presentation skills, and the development of their skills as performers. Whilst sessions might be audio or videotaped and the recordings made available for students to peruse, all too rarely do some engage critically with their performance. Many students, in fact, assume a passive role in assessing their performances critically, relying primarily on others for feedback. Regardless of the reasons for this, be it apathy or trepidation at analysing the performances, the lack of engagement can retard the development of performance skills. To what extent might music institutions and pedagogues have been neglecting a fundamental emphasis in this area? What are music institutions doing to ensure the development of motivators for internal assessment? Should we assume that the majority of students will develop their own form of self-critical assessment? To what extent have we the responsibility to design and introduce such processes into university music training?

Several academics comment on the issues of independent or self-directed learning and self-assessment within university music curricula. Simone de Haan (1998: 244) argues that it is crucial that music institutions 'encourage students to take responsibility for their own learning'. Lee (1997: 112) argues that for students to be truly self-directed, they 'have to learn to assess their own progress'. Murray-Harvey (1997: 175) 'uses the assessment process as a way of encouraging students to take more responsibility for their learning' and involves the students directly in the grading of assessable work. This suggests that it is potentially viable for students to gain greater control over the development of their performance skills if they are encouraged or required to take part actively in the assessment process.

Partially as a response to the above challenges, a new method of assessment of performance was introduced at James Cook University in 2000. Traditionally, Concert Practice classes in music involved students performing under professional conditions, with lecturers assessing the performance and allocating a numerical mark based on a set of criteria. Students were required to play in the class twice during each semester. Although some students may have reflected on their performance either by themselves or in consultation with their teacher, there were no specified assessable criteria for analysis or reflection. This new method of assessment involved the introduction of a self-reflection and analysis component as part of course requirements. Students were required to collect a video-tape recording as soon as possible after their Concert Practice performance, view it as many times as was necessary or appropriate, and then write a 300-word self-critical reflection on their performance. The guidelines for the report specified critical comment on the following aspects and issues: 
- Personal presentation - entrance and exit, bowing, physical presence, characteristic mannerisms, etc.;

- Musical issues - accuracy, stylistic appropriateness, choice of repertoire;

- Overall impression - personal response, audience response;

- Reflections on actual performance via viewing the video as against perceived performance;

- Reflections on progress - improvements and developments since previous performance; and

- Directions - plans to improve and enhance performance.

The students were required to submit their self-assessment report no later than one week after their performance, ensuring the review of their performance was carried out while it was relatively fresh in their eyes and ears. For the report they were awarded a grade, based on the insights and comments made in relation to the specified criteria for reflection. Staff would also assign the student a numerical mark for performance, based on the following criteria of assessment:

- Musical literacy;

- Technical facility and accuracy;

- Interpretative skills; and

- Professional presentation.

The marking process thus became two-fold, with the student's reflective contribution playing an equal part (50 per cent) in the assessment of their performances. Students were also required to discuss with their instrumental teachers the issues raised during the performance and via the writing of the self-critical report. Whilst the student report was relatively brief, the process of engaging in analysis of the performance via video observation and written critique presented a platform for further discussions between the students and their teachers.

\section{The questionnaire}

The next step in the process of evaluating the success of this project was to review it. At the end of the academic year 2000, all thirty-five full-time performance students enrolled in the Bachelor of Music degree completed a questionnaire. The students were at first-, second- and third-year levels. The questionnaire dealt specifically with the twelve-month trial process initiated as part of the music degree course. It covered three areas:

- Personal details;

- Background training and previous methods of assessment of performance; and

- The trial process.

\section{Personal details}

The majority of the students were female ( 77 per cent). Half were less than twenty years of age, 34 per cent were aged twenty to twenty-five years of age, and 17 per cent were above twenty-five. The majority (54 per cent) were instrumentalists, 29 per cent were pianists and 
17 per cent were singers. Of the instrumentalists, 68 per cent were wind players, 16 per cent brass players and 16 per cent were guitarists. At the time, no string players had enrolled in the degree course.

Background training and previous methods of assessment of performance

Table 1 demonstrates the learning environments of the students prior to university study.

Table 1 Breakdown of forms of tuition/learning and relevant percentages

\begin{tabular}{ll}
\hline \hline Individual lessons & $94 \%$ \\
Bands/Orchestras & $63 \%$ \\
Classroom music & $57 \%$ \\
Group tuition & $26 \%$ \\
Other (masterclasses, books/tutors, self-teaching) & $14 \%$ \\
\hline \hline
\end{tabular}

As expected, virtually all of the students had engaged in musical study via individual lessons. The next question was concerned with how frequently the students experienced different types of feedback of their performances prior to entering university. Table 2 outlines the types of feedback and how often students utilized these different forms of appraisal of performance.

Table 2 Forms of feedback of performance identified by students

\begin{tabular}{lcccrr}
\hline \hline Type of feedback & $\begin{array}{c}\text { Very } \\
\text { frequently }\end{array}$ & $\begin{array}{c}\text { Somewhat } \\
\text { frequently }\end{array}$ & Occasionally & Rarely & Not at all \\
\hline Audiotaping & $9 \%$ & $9 \%$ & $11 \%$ & $25 \%$ & $46 \%$ \\
Videotaping & $9 \%$ & $17 \%$ & $17 \%$ & $20 \%$ & $37 \%$ \\
Teacher's comments & $57 \%$ & $17 \%$ & $9 \%$ & $6 \%$ & $11 \%$ \\
Other student's comments & $9 \%$ & $22 \%$ & $31 \%$ & $29 \%$ & $9 \%$ \\
Audience comments & $17 \%$ & $29 \%$ & $34 \%$ & $17 \%$ & $3 \%$ \\
Family comments & $17 \%$ & $35 \%$ & $14 \%$ & $14 \%$ & $20 \%$ \\
\hline \hline
\end{tabular}

The majority indicated that they very frequently relied on their teacher's comments. This resulted from the fact that nearly all the students had engaged in individual lessons prior to university. Audio and videotaping were used rarely or not at all. The majority indicated that they had very limited or no access to audio- or video-recording equipment.

Those who did have access to recording equipment were asked to identify how often they used this to record performances for feedback purposes. The results are outlined in Table 3.

These statistics again reflect reliance, or over-reliance, on teachers' comments. It also potentially demonstrates the lack of pursuit of these forms of assessment by the students' teachers.

Students were then asked to what extent their teachers expected them to evaluate their own performances (see Table 4). 
Table 3 Frequency of student access to video- and audio-recording equipment

\begin{tabular}{lcc}
\hline \hline Rate of access & Audio-recording equipment & Video-recording equipment \\
\hline Weekly & $10 \%$ & $5 \%$ \\
Monthly & $5 \%$ & $5 \%$ \\
About once a term & $17 \%$ & $15 \%$ \\
From time to time & $46 \%$ & $42 \%$ \\
Never & $22 \%$ & $33 \%$ \\
\hline \hline
\end{tabular}

Table 4 Teacher's expectation for student's self-evaluation of performance

\begin{tabular}{ll}
\hline \hline As a matter of course & $11 \%$ \\
Frequently & $17 \%$ \\
Sometimes & $31 \%$ \\
Rarely & $17 \%$ \\
Not at all & $24 \%$ \\
\hline \hline
\end{tabular}

The majority (72 per cent) indicated that they were required to evaluate their own performances from 'sometimes' to 'not at all', reflecting a continuum of reliance on teachers for the primary means of assessing their performances.

The trial process

In this section of the questionnaire, students were asked how they initially reacted when being told that this process of self-assessment via video recordings and self-critical reports was part of the requirements of their course (see Table 5).

Table 5 Reactions to introduction of new self-assessment procedures

\begin{tabular}{lr}
\hline \hline I was terrified & $11 \%$ \\
I did not know how I would cope & $6 \%$ \\
I was not at all concerned & $29 \%$ \\
I considered it a personal challenge & $29 \%$ \\
I was looking forward to the process & $25 \%$ \\
\hline \hline
\end{tabular}

The results indicate that just over half the students were in a relatively positive frame of mind at the introduction of this process. The ten who indicated that they were 'not at all concerned' may have been reflecting a nonchalant attitude or indicating that they were secure with the thought of engaging in this activity.

When the students were asked to describe their reactions when they first viewed their performances on video, the responses varied, with approximately half of a positive nature. Table 6 categorizes and summarizes the responses and provides relevant examples. 
Ryan Daniel

Table 6 Initial student reactions to viewing their performance on video

\begin{tabular}{|c|c|c|}
\hline Type of comment & $\begin{array}{c}\text { Number of comments } \\
\text { as a percentage }\end{array}$ & Examples of relevant comments \\
\hline Technical & $11 \%$ & $\begin{array}{l}\text { 'My hand position was incorrect' } \\
\text { 'I was surprised at my tone quality and excited to } \\
\text { hear where I could improve' }\end{array}$ \\
\hline General/Overall & $31 \%$ & $\begin{array}{l}\text { 'I could see things I didn't know I was doing' } \\
\text { 'It was very different to how I played' } \\
\text { 'Surprised' } \\
\text { 'Nothing I wasn't already aware of' }\end{array}$ \\
\hline Critical & $43 \%$ & $\begin{array}{l}\text { 'I felt disappointed with my efforts' } \\
\text { 'I looked dreadful' } \\
\text { 'I thought I looked funny' } \\
\text { 'Horrified' } \\
\text { 'I hated it' }\end{array}$ \\
\hline $\begin{array}{l}\text { Self- } \\
\text { congratulatory }\end{array}$ & $6 \%$ & $\begin{array}{l}\text { 'It was not as bad as I thought it would be' } \\
\text { 'It was better than I thought' }\end{array}$ \\
\hline No comment & $9 \%$ & \\
\hline
\end{tabular}

A significant number of the students (43 per cent) were very critical of their own playing or performance, suggesting that they,

- found the process strange due to their unfamiliarity with it;

- found it difficult to analyse their own performances objectively;

- were overly critical of themselves; or

- may look negatively on themselves and their performance skills.

When asked to comment on how they felt about the process after twelve months, the majority (86 per cent) felt that the procedure was very valuable. Comments included:

- 'It helps to realize the mistakes, errors and what needs improving';

- II feel it helps';

- 'It is an excellent way to focus on or find your areas of difficulty';

- Il look forward to seeing [the video] and watching for improvements';

Two respondents did not understand the question, while three felt the same as when they first started the process. These students still found the process a largely negative experience:

- 'It's still no fun watching myself';

- II feel about the same (embarrassed)';

- 'I still hate it and can't go and watch [the video]';

The next question asked to what extent students felt their judgement of the performance on video was in accord with their view of the performance after exiting the stage (see Table 7). 
Table 7 Views of video analysis related to impressions at time of performance

My view is about the same regardless $14 \%$

I tend to see the performance as better than I felt it was at the time $\quad 37 \%$

When I see the video I tend to see/hear my faults more clearly than at the $\quad 49 \%$

time of the performance

The results are interesting in that almost half of the students see and hear more problems on viewing the video. This statistic should prove invaluable for students and their teachers in providing a resource and reference tool to base further investigation of the performance and thereby to enable improvements in subsequent practice. It also suggests that students who do not analyse their own performances via video may, in fact, miss many of the 'problems' that are encountered during the live performance.

The following question asked students about the extent to which the writing of selfcritical reports had enhanced their performance skills. The possible responses, tabulated in the left hand column of Table 8 , are as follows:

1 to a very significant degree;

2 to a moderate degree;

3 to some degree;

4 to a small degree; or

5 not at all.

Table 8 Student responses to value of self-critical reporting in enhancing performance skills

\begin{tabular}{lcl}
\hline \hline Response & Number of Responses & Percentage \\
\hline 1 & 4 & $11 \%$ \\
2 & 16 & $46 \%$ \\
3 & 10 & $29 \%$ \\
4 & 4 & $11 \%$ \\
5 & 1 & $3 \%$ \\
\hline \hline
\end{tabular}

More than 80 per cent of the students felt that the process of writing these reports enhanced their performance skills to some, a moderate or a very significant degree. Only 14 per cent felt that it did not enhance their performance skills to any great degree.

Students were then asked to indicate what they felt were the advantages and disadvantages of the process of videotaping and writing self-critical reports. All students found numerous advantages in both these processes (see Table 9).

It is interesting that seventeen of the thirty-five students found no problems at all with videotaping. The most significant problem was not inherent in the process, but a technical problem with the quality of sound, which twelve indicated was not entirely satisfactory. The majority of students (63 per cent) stated that there were no disadvantages in the writing 
Table 9 Responses to question of advantages and disadvantages of processes introduced

Videotaping - Advantages (summarized) Videotaping - Disadvantages

- you are able to see your performance

- you can see the problems and then try to fix them

- it is good to see how you react in the performance arena

- $\quad$ it allows the student to assess themselves from an audiences point of view

- allows you to pinpoint specific areas of difficulty

Self-critical reports - Advantages (summarized) Self-critical reports - Disadvantages

- forces you to really look at your performances and how to improve

- you have to concentrate on the performance afterwards rather than just dismissing it

- it makes you think about the performance before the next one

- you learn to become more aware of what you're doing and why
- $\quad$ none (17)

- often makes new performers nervous

- $\quad$ quality of sound on the tape (12)

- depending on the situation, I become shy and don't play as well

- $\quad$ people don't like to be watched by cameras
- $\quad$ none (22)

- $\quad$ often pick on yourself too much (2)

- I think a student should think and work through problem areas without having to write a report

- It brings down self-esteem if you are constantly criticizing yourself

- Time consuming

- We have enough work to do

of self-critical reports, although there were certain comments of concern. Two stated that the process meant that they would pick on themselves 'too much' and one indicated that the process 'brings down self-esteem'. These responses raise the issue of whether selfcritical analysis for some may in fact counteract creativity. Whilst it can be argued that these students may be highly sensitive or less able to analyse their performances objectively, it does suggest that the process needs to be monitored carefully by pedagogues and academics, to ensure that students' creativity and spontaneity do not suffer as a result of self-critical analysis. It also suggests that pedagogues stress that the process is designed to be positive in assisting students to develop their performing and analytical skills.

Students were then asked to what extent they would recommend as valuable to other performers the practice of videotaping as a basis for self-critical reflection (see Table 10).

Table 10 Responses to the value of the introduced process

\begin{tabular}{lr}
\hline \hline Highly valuable & $57 \%$ \\
Moderately valuable & $26 \%$ \\
Somewhat valuable & $11 \%$ \\
Not overly valuable & $3 \%$ \\
Not at all valuable & $3 \%$ \\
\hline \hline
\end{tabular}




\section{Conclusions and implications}

The responses to the questionnaire demonstrate that the new method of assessment introduced provided a range of benefits for the group. Although some experienced difficulties with the processes, the benefits indicated by the majority suggest that the procedures introduced be continued. Whilst it is inevitable that some will find this type of self-examination difficult, it is potentially a case of careful management by the staff concerned, which may lead to a more beneficial experience for these students. The data suggest that the process can be an extremely valuable tool in tertiary institutions. Whilst not superseding a teacher's or mentor's comments, this procedure potentially leads to a greater level of student independence in assessing their performances. Obviously, a highquality recording is essential, as the comments from students indicate. This issue needs to be addressed realistically prior to commencing such a method of assessment. The selfcritical reports are not only an excellent basis for teachers and students to proceed with discussions about the performance, but they also provide students with a record of their progress over time. The writing of reports also serves to develop critical skills that are essential to any student interested in pedagogy at various levels. With regard to performance, the process serves to further develop students' self-reflective skills that, once they have graduated, are crucial to their career prospects in the profession.

\section{References}

BAKER-JORDAN, M. (1999) 'What are the pedagogical and practical advantages of "three or more" teaching?' In Pedagogy Saturday III, pp. 22-3. Cincinnati: Music Teachers National Association.

BENSON, C. (2000) 'Forum on group piano: achieving individual and group success'. Piano Pedagogy Forum, 3, 1, online publication: (www.music.sc.edu/departments/piano/ppf/3.1/3.1.PPFgp.html)

CARTY, P. (2000) 'Thought for the newsletter - a video portfolio'. U.K. Piano Teachers Group Newsletter, 103, 20 May.

DE HAAN, S. (1998) 'The relationship between the composer, performer and listener in twentieth century music-making'. In R. Payne (Ed), The Australian Music Teacher Magazine, 6, 9, 238-46.

FRANCIS, D. (1997) 'Composing student learning'. In J. Bain, R. Ballantyne and J. Packer, Reflecting on University Teaching: academics' stories, pp. 131-7. Canberra: Australian Government Publishing.

GUILDHALL SCHOOL OF MUSIC \& DRAMA (n.d.) Examples of the Way in Which PCS Promotes Reflective Practice (course outline), pp. 32-4.

HORN, K. (1996) 'Calling a halt to the flat earth theory in music and education: cultural diversity versus cultural standardisation'. In Brenton Broadstock et al., Aflame with Music: 100 years of music at the University of Melbourne, pp. 535-43. Melbourne: Centre for Studies in Australian Music.

JAY, H. (2000) 'Videos and recording'. U.K. Piano Teachers Group Newsletter, 104, 27 May.

LEE, P. (1997) 'From control to trust - a case study of problem-based learning'. In J. Bain, R. Ballantyne and J. Packer, Reflecting on University Teaching: academics' stories, pp. 101-16. Canberra: Australian Government Publishing.

LYNCH, M. (1998) 'Getting it taped'. Music Teacher, 77, 10, 40-41.

MURRAY-HARVEY, R. (1997) 'Assessment for learning: students in control'. In J. Bain, R. Ballantyne and J. Packer, Reflecting on University Teaching: academics' stories, pp. 175-81. Canberra: Australian Government Publishing.

MUSIC TEACHERS NATIONAL ASSOCIATION (1999) Pedagogy Saturday III, Cincinnati: Music Teachers National Association. 
Ryan Daniel

RENSHAW, P. (2000) 'Sustaining a learning culture in arts training institutions'. European Journal of Arts Education, 3, 1, n.p.

ROSS, M., RADNOR, H., MITCHELL, S. \& BIERTON, C. (1993) Assessing Achievement in the Arts. Milton Keynes: Open University Press.

SMYTHE, R. (2000) 'Off the record'. Music Teacher, 79, 2, 17.

STOWASSER, H. (1996) 'Creative students need creative teachers'. In Brenton Broadstock et al., Aflame with Music: 100 years of music at the University of Melbourne, pp. 545-55. Melbourne: Centre for Studies in Australian Music.

WILLS, G. (2000) 'The music schools in the year 2000'. Music Forum, 6, 6, 16-18. 